\title{
Great challenges to PMTCT in the South: the role of the developed nations in supporting strategies that work Dorothy Onyango
}

\author{
Address: Women fighting AIDS in Kenya (WOFAK), 00200 Nairobi, Kenya \\ from Fourth Dominique Dormont International Conference. Host-Pathogen Interactions in Chronic Infections \\ Paris, France. 13-15 December 2007 \\ Published: 9 April 2008 \\ Retrovirology 2008, 5(Suppl I):LI doi:I0.II86/I742-4690-5-SI-LI
}

This abstract is available from: http://www.retrovirology.com/content/5/SI/LI

(C) 2008 Onyango; licensee BioMed Central Ltd.

\section{Introduction}

Prevention of mother to child transmission of HIV (PMTCT) has continued to gain immense significance in the fields of HIV prevention and care, mostly in the last 10 years. This significance has come about due to the growing recognition that HIV is not only in blood and sexual fluids but also in breast milk. The fact that over $58 \%$ of all infections in sub-Saharan Africa are found among women in reproductive ages (19-49 years) makes PMTCT a life and death subject.

In Africa, women face the ravages of HIV/AIDS in uneven proportions; they often bear the heaviest brunt of the epidemic, as caregivers, as persons living with HIV/AIDS and as the pivotal points of every society. When they are infected, their roles in society do not change much, as often, the society still expects them to play their parts as ever before.

It is estimated that about $30 \%$ of all babies born to HIV positive mothers will acquire the virus. Our experiences show that this percentage only talks of the ones that will get the virus either in the womb or during delivery. We suspect that a bigger fraction get the virus through breastmilk.

In developed countries, almost all HIV infected women will receive good PMTCT care. With the best treatment and formula feeding, the chance of HIV being transmitted to the baby is less than two percent. In developing countries it is very different. While a few developing countries have launched effective responses, on average less than ten percent of women receive even the most basic PMTCT services. (Source: The Stop AIDS in Children Campaign).
As a result, around half a million children are infected with HIV every year. Why are so many pregnant women not receiving the help they need? Most often it is because PMTCT services are unavailable or inefficient, or because women are unable to access them. Stigma and fear may also play a role by making a woman unwilling to take an HIV test, or unwilling to take PMTCT drugs. These problems, though challenging, can be overcome. Some developing countries, such as Botswana and Brazil, are already providing PMTCT services to most of their pregnant women.

\section{PMTCT: The grim picture in the South}

Africa South of the Sahara is a grim picture of the struggle of mothers living with HIV/AIDS to deliver safe uninfected babies. The African woman who is living with HIV/ AIDS and does not have her rights to making informed choices on sexuality and child-bearing, the woman who does not have her own money to go for treatment, to access competent antenatal and postnatal care services, who does not have the ability to travel long distances to access HIV testing and related care, will most certainly beget a baby who is infected with HIV.

In many African Countries, uneven distribution and infrastructural inadequacies of existing PMTCT services make them ineffective and unattractive to many would-be -beneficiaries. Access to PMTCT services and community knowledge around mother to child transmission (MTCT) remain low. The existing PMTCT sites are battling with what has been christened as "minimum package", that is to say, that at least "something" that would help reduce chances of mothers transmitting the infection to their babies. It is the height of all inadequacies. For how long will women contend themselves with "minimum package" of PMTCT? 


\section{The role of the developed countries}

The reality of PMTCT in Sub-Saharan Africa is that many women in the reproductive ages still continue getting infected and many are still unable to access competent treatment and PMTCT and care services. It is still a fact that there are structural inadequacies in the current setups of PMTCT sites as they have aimed too low at getting "a minimum package", thus losing great opportunities to reduce mother to child infections to around $2 \%$ as in developed countries.

The developed world has a moral duty to support scaling up strategies that have been proved to work. These strategies include:

- Improving distribution of PMTCT centres, especially with facilitation of the community based organizations that have the capacity to undertake this.

- Improving quality of PMTCT services to move away from "minimum package" to a near-comprehensive package, thus drastically reduce chances of mother to child transmission of HIV.

The near-comprehensive position of PMTCT that we call for includes but not limited to the following:

- Supporting mothers to access competent and timely treatment services, including ART and other drugs for opportunistic infections.

- Supporting mothers to access adequate nutrition that also includes supportive supplements such as multivitamins.

- Supporting mothers to access safe delivery services including caesarean section as per the advice of qualified personnel.

- Supporting mothers to access alternative feeding opportunities for their babies if they wish, even though this option still remains quite controversial.

\section{Conclusion}

African women living with HIV/AIDS have a burning desire to beget children who are free from HIV/AIDS. Their resolve is unparalleled, their readiness is unquestionable. What they lack are the resources to achieve these aims. It is our appeal that PMTCT should get more elaborate support from the developed world, to ensure that we shall no longer talk of "minimum package of PMTCT" but a comprehensive package that ensures that babies are born without HIV infection.

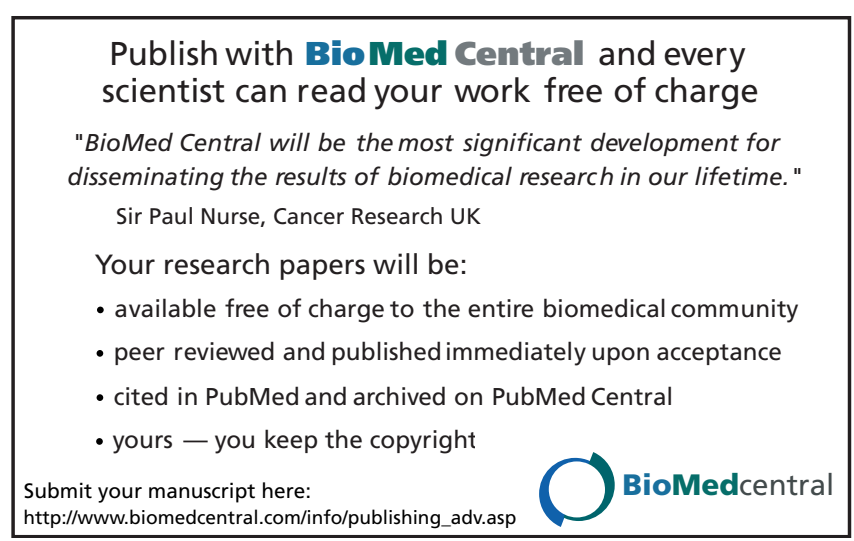

Page 2 of 2

(page number not for citation purposes) 